\title{
Digital Video and 'e-cinema'
}

\author{
By Brandon Wee
}

Fall 2000 Issue of KINEMA

\section{NEW HORIZONS: DIGITAL VIDEO AND 'E-CINEMA'}

When digital video (DV) was introduced to the consumer market in 1994, it would have been difficult to visualise it as a medium predestined to cast a shadow over the future of filmmaking. Vulcanised on the advances in digital technology, DV would not only proselytise a slew of economical and mechanical gambits to its superiorly endowed counterpart, but also attempt to wrestle power and centrality from it. And now, more than half a decade on, filmmakers around the globe are either basking in DV's therapeutic warmth or shunning its unsavoury heat.

In contemporary Singapore, where the omnipresent label 'film industry' is a categorical misnomer, and where the financial realities of using film constitute a perennial cul-de-sac, DV has unsurprisingly been embraced as the alchemic alternative. Earlier in March, the Substation (a non-profit centre for the arts) organised a groundbreaking seminar on the business at hand, aptly titled Going Digital. What was to be expected from the event, indeed, was the usual discourse and networking -- but the outcome was undeniably a watershed. For closeted and emerging talents in the field of video and cinema, DV is a bracing antidote to the potentially paralysing side effects of using celluloid film.

The pioneering DV feature Return to Pontianak (slated for general release early next year) by award-winning filmmaker Djinn is a manifestation of this revelation. Shot on Sony's VX-1000 camera (the 'granddaddy' of mini-DV cameras that popularised the format) before being blown up to $35 \mathrm{~mm}$ print and touted as "a low budget misadventure", the 81-minute horror film, footed by new production company Vacant Films, is a modern adaptation of the traditional Malay Pontianak (female demon) stories popular in the 1950s and 60s; the new version is starring an international cast led by Asian-American actress Hiep Thi Le.

"We couldn't afford 35mm equipment, so DV was a good option to explore," reasons writer-director Djinn, adding that they were "shooting on DV not to champion the advancement of (the medium), but because of (its) affordability." Costing $\mathbf{S} \$ 20,000$, Pontianak's bill would have been three times higher if it had been shot on film -- peanuts on paper, but not when one considers the empirical adage that films in commercial release in Singapore are pressured to recoup, conservatively estimating, three-and-a-half times their budget at the box office in order to break even. In the afterglow of local distributor Shaw Brothers' endorsement of Pontianak through an offering of a three-picture deal with Vacant, Djinn adds that the "we're-not-interested-in-youbecause-local-filmmakers-don't-make-money" mentality prevalent among local investors and distributors may soon be dispelled.

Having said that, DV's fiscal viability does not come without some gold trimmings, such as the physical appeal of equipment portability and mobility. "Logistically, it's liberating," comments producer Juan Foo on the multi-tasking nature of the shoot. "There were no more than five crew members at any one time... and everybody doubled up in roles. Even the actors helped out... from buying food to carrying equipment to clearing sets; one of them became soundman for us in between his takes." Adds Djinn on the fact that his team's reliance on DV had greatly subtracted costs on apparatus, set-up time and manpower: "We were rebels without a crew and equipment."

While international filmmaking communities are still by all accounts polarised in opinion over the value of DV, many in Singapore will certainly be observing the medium's proliferation, invariably with vested interests. Pontianak will arrive only months after Stories About Love, another pioneering digital feature comprising an anthology of shorts written and directed by filmmakers James Toh, Abdul Nizam and CheeK. Shot evenly over three weeks at a cost of $\$ 300,000$ on Sony DVW-700P digital beta cameras, the finished work had the privilege of being screened in its original format via a digital projector on top of being transferred to $35 \mathrm{~mm}$ print to suit conventional film projectors.

Hailing digital technology as "instantaneous", producer Eric Khoo rhapsodises that "cost-effective budget filmmaking will go a long way with digital." He adds that had Stories been afforded celluloid treatment, its 
grand total would have gestured close to $\$ \$ 900,000$. Further, he declares that the medium "presents no negative attributes" since post-production by way of digital editing systems can be managed domestically, where content can be stored, manipulated and relayed handily within the domain of computers. Echoing Khoo's enthusiasm is executive producer Geoff Malone, founder of the Singapore International Film Festival (SIFF), whose new film company Cyberflics spearheaded Stories.

But for all the acclaim that 'digital filmmaking' is currently rolling in, there is the contentious issue surrounding digital technology's appropriation of the traditional film medium that celluloid purists seek to redress. "DV is best used by novice directors who no longer have to wait five years for someone to take a chance on their projects," declared veteran director Brian De Palma during the release of his spring flop Mission to Mars (2000). But up-and-coming Karyn Kusama harboured a more objective stand at Cannes recently: "What's disturbing to me is that we're so seduced by the deceptive convenience of digital filmmaking that we forget the beauty of filmmaking is that it's difficult, and that the texture requires so many choices to create something great. And those choices are part of the process of making art."

Back home, Khoo reminisces that during pre-production on his previous feature 12 Storeys (1997), he had in his palms a VX-1000, which made him consider embarking on a DV shoot. Its promise of crisp images stemming from its high-resolution capability notwithstanding, Khoo's cinematographer had discouraged this because of the gamut of expressive textures that could only be attainable on film -- just like how the blunt and uninhibited audibility from a compact disc will always be eclipsed by a vinyl's caramelised resonance. Similarly, the trio of cinematographers lensing Stories had to prioritise several technical considerations, foremost of which was this: since video's hard-edged contrast can ebb dramatically when blown up for projection or when exposed onto photographic film to obtain prints, caution had to be observed during certain aspects of the shoot, such as the lighting of scenes and angling of shots.

Admittedly, DV is not film, but the reverse is equally true. Case in point: The Cruise (1998), an astonishing black-and-white documentary painting an abstract self-portrait of the Big Apple's 'iconic' tour guide, Timothy 'Speed' Levitch. Armed with a VX-1000, director Bennett Miller had expedited a 3-month shoot of 100 hours of footage with a shoestring crew that would cause (and cost) any tenacious purveyor of celluloid to do a double take. The feature's crowning glory however, was apparent in its inimitable style that honoured sensuality and sensibility alike -- affirmation of the unbridled scope of experimentation attainable with the medium. Miller nevertheless warned that while DV affords a less expensive shoot, the process of ultimately transferring the movie to celluloid could prove pricey and taxing.

And yet, if dissent on DV's abilities is unyielding, then assent is conversely unequivocal. Mike Figgis, whose experimental Timecode (2000) has been hailed as Hollywood's freshest and most bankable plat du jour, extols the 'digital revolution' in an interview with indieWIRE: "...Every time you stop and think about the technology, ten ideas emerge of how you could have fun and push the creative barriers, because of this amazing [...] appearance of this availability of transmission... I can go to Moscow, make a film in 5 days (and) transmit it on the $6^{\text {th }}$ night (via the Internet)..."

Indeed, this democratisation of cinema that Figgis alludes to is nothing if not a gripping prospect. With the encroaching evolution of streaming technologies, the arena of the 'shorts' -- commercials, music videos and cinema -- has become the preordained beneficiary of the Internet's largesse, with a hoard of online marketing and distribution avenues springing unremittingly to accommodate their propagation. For short filmmakers in particular, this represents a new creative opportunity, for akin to television's endorsement of short films as feasible programming content, the Internet enshrines this underrated category by providing ease of access to a broad audience.

Says Chang Chee Young, founder of Subfilms.com, a Singapore web site committed to the development of Asian short films with a three-armed mission of web casting, production and community building: "With the advent of DV, I daresay an upsurge of filmmakers will flourish because the medium blesses the filmmaking process with accessibility. The net result of this is therefore twofold: DV makes it cheaper to make films while the Internet makes it cheaper to distribute them." But as Peter Schoppert, Senior Vice President of Asiacontent.com that manages 8arts.com confesses, that despite an interest, "short films are notoriously hard to distribute (online)," attributing the problem to a paucity of decent local broadband infrastructure and penetration. "Everyone clamours for better bandwidth -- it's a fact of life," he adds, believing however that 
the demand for 'video on-demand' will greatly increase over the next few years. "It's an exploration," he notes on his organisation's mutually advantageous partnership with SIFF, which contributes programming expertise by commissioning new 'shorts' from established Asian independent filmmakers, while 8arts provides online marketing and distribution strategies to target local, regional and eventually, global audiences.

Interestingly, history was made in June 2000 when $20^{\text {th }}$ Century Fox's animated deep-space epic Titan A.E. was transmitted over a secure Internet-based network in the US, from California to Atlanta, where it was digitally projected to an audience. Ironically, the studio that made the film has since closed down.

"Ultimately however," cautions Chang, "DV and film are just tools of the trade. If good stories are available, then it doesn't matter what format or form they are articulated or distributed in. Audiences go for compelling tales; they don't think: "Hey, this film is shot on DV, let's go watch it since it's of better quality." His point is a significant criticism of this controversial 'digital revolution' because the art of cinema will always be a feston of aesthetics and technology, where neither is mutually exclusive. Digital video and its related technologies certainly do not privilege nor constrain either entity; they are merely functional implements capable of aiding form, but not having the means to dictate it.

(This article is based on a similar text by the same author published by the Arts Magazine, Esplanade Co. Ltd., September/October 2000.)

\section{Notes}

Note on Digitalvideomaking (proximity of words is deliberate)

Although generic usage of the term 'digital video' is problematic owing to the prevalence of a range of digital tape formats on the consumer market, the term (also called "mini-DV" in its smallest tape form) essentially refers to either video/audio -- of analogue source content or otherwise -- that is stored in a digital tape format, or video/audio that is viewed or manipulated -- by way of non-linear editing -- in the realm of computers. All the buzz surrounding the hotly debated 'digital revolution' rests not only in the availability of comparatively inexpensive production (DV cameras and equipment) and post-production facilities (desktop editing systems and tools) and modes of distribution (CD-ROM, DVD or the Internet), but more importantly, that these methodologies have been centralised for domestic consumption. Hypothetically estimating, anyone in possession of a DV camera and associated equipment, DV cassettes, a low-end DV editing system installed on their home Macintoshes or PCs, and a zealous and spirited disposition (priceless) can afford to produce a quality movie.

For further technical reading on digital video, check out the following web sites:

Adam Wilt's DV, DVCAM \& DVCPRO Formats (http://www.adamwilt.com/DV.html)

\section{Author Information}

Brandon WEE lives in Toronto. He has written for Asia Pacific Arts (Los Angeles), Cineaste (New York), Cinema Scope (Toronto), Ricepaper (Vancouver), and Senses of Cinema (Melbourne). 